\title{
OS MIGRANTES E REFUGIADOS, OS IMPACTOS DA COVID-19: RESPOSTA, POR MEIO DE PLANOS E DADOS
}

\author{
Wellington Boigues Corbalan Tebar, Edinilson Donisete Machado \\ Universidade Estadual do Norte do Paraná - UENP, PR. E-mail: wellingtontebar@hotmail.com
}

\section{RESUMO}

Este trabalho visou analisar, de uma maneira geral, a situação dos migrantes e refugiados frente às adversidades geradas pela pandemia de COVID-19. Notou-se, nesse período, a vulnerabilidade desses grupos de pessoas, seja pelos comportamentos de exclusão da sociedade em que estão inseridos, seja pelas medidas tomadas pelos governos para contenção dos impactos da doença, bem como mitigação dos seus efeitos. Para tanto, foram apresentados dados, referentes aos principais impactos gerados pela crise sanitária, bem como recomendações para que os Estados Nacionais elaborem planos de resposta adequados. Verificou-se que a situação dos campos de refugiados também é preocupante. $O$ confinamento de várias pessoas, num mesmo local, cujo número muitas vezes excede à capacidade de ocupação, somado às precárias condições de saúde, higiene e saneamento básico, facilita a propagação do vírus, tornando-se alvos fáceis da doença. Por isso se concluiu que, a medida que a situação de vulnerabilidade se agrava, por conta da evolução da pandemia, tão mais eficazes devem ser as respostas a serem dadas pelos governos nacionais para garantia dos direitos humanos a esse grupo de pessoas. A pesquisa tomou, como referência, documentos oficiais elaborados por organismos internacionais (de nível global e regional) de proteção dos direitos humanos. E foi usado como método o exploratório-descritivo, com abordagem qualitativa, pois se procedeu à análise de documentos oficiais, elaborados por organismos internacionais (de nível global e regional) de proteção dos direitos humanos.

Palavras-chave: Crise Sanitária. Grupos Vulneráveis. Migrantes e Refugiados. Violação de Direitos Humanos.

\section{MIGRANTS AND REFUGEES, THE IMPACTS OF COVID-19: RESPONSE, THROUGH PLANS AND DATA}

\section{ABSTRACT}

This paper aimed to analyze, in general, the situation of migrants and refugees in the face of the adversities generated by the pandemic of COVID-19. During this period, the vulnerability of these groups of people was noted, either by the exclusionary behaviors of the society in which they are inserted, or by the measures taken by the governments to contain the impacts of the disease, as well as mitigation of its effects. To this end, data were presented, referring to the main impacts generated by the health crisis, as well as recommendations for National States to develop adequate response plans. It was found that the situation in the refugee camps is also worrying. The confinement of several people, in the same place, whose number often exceeds the occupation capacity, added to the precarious conditions of health, hygiene and basic sanitation, facilitates the spread of the virus, becoming easy targets of the disease. That is why it was concluded that, as the situation of vulnerability worsens, due to the evolution of the pandemic, so much more effective must be the responses to be given by national governments to guarantee human rights to this group of people. The research took, as a reference, official documents prepared by international organizations (global and regional level) for the protection of human rights. And the exploratory-descriptive method was used, with a qualitative approach, as official documents were analyzed, prepared by international organizations (at global and regional level) for the protection of human rights.

Keywords: Sanitary Crisis. Vulnerable Groups. Migrants and Refugees. Violation of Human Rights. 


\section{INTRODUÇÃO}

Parece ser consensual que a pandemia de COVID-19 tem potencial ilimitado para afetar, negativamente, vários grupos de pessoas, especialmente aqueles classificados como vulneráveis. Neste sentido, este trabalho científico teve por objeto analisar, em aspectos gerais, a situação dos migrantes e refugiados frente às adversidades geradas pela pandemia de COVID-19.

Neste sentido, o desenvolvimento deste estudo é dividido em três etapas. Em primeiro lugar, foram apresentados dados que evidenciam os impactos que a pandemia de COVID-19 gerou (e está a gerar) em relação aos migrantes e refugiados. Por outro lado, em segundo lugar, foram apresentadas as diretrizes que devem ser seguidas pelos Estados nacionais, quando da elaboração dos planos de resposta à pandemia, em relação aos migrantes e refugiados.

Por fim, para a elaboração deste trabalho, quanto ao método de pesquisa, foi utilizado, principalmente, o método exploratóriodescritivo, com abordagem qualitativa, pois se procedeu à análise de documentos oficiais, elaborados por organismos internacionais (de nível global e regional) de proteção dos direitos humanos.

\section{IMPACTOS DA PANDEMIA DE COVID-19}

A pandemia de COVID-19 acentuou a situação de vulnerabilidade a que determinados grupos de pessoas estão submetidos, tais como os idosos, as crianças e mulheres, as pessoas com deficiência, bem como os deslocados internacionais, que englobam, aqui, os refugiados, os solicitantes de asilo, os migrantes, os deslocados (notadamente os forçados) e os apátridas ${ }^{1}$.

Este artigo trata especificamente dos deslocados internacionais, de modo que, neste tópico, serão apresentados os principais impactos gerados pela pandemia de COVID-19 em relação a esse grupo de pessoas, tendo em vista documentos, notas e boletins emitidos por

\footnotetext{
${ }^{1}$ Grupos vulneráveis de pessoas são aqueles que estão expostos, de maneira desproporcional, a determinados riscos, tais como violência e abusos sistemáticos de direitos, por não possuírem capacidade efetiva de reação. Em contexto de pandemia, se a política pública, formulada pelo Estado como resposta à contenção de seus efeitos, for insatisfatória (ou mesmo inexistente), a vulnerabilidade pode vir a alcançar outros grupos de pessoas, em razão, por exemplo, do influxo de novos fatores, de cunho socioeconômico, financeiro, de saúde mental, dentre outros (THE LANCET, 2020, p. 1.089).
}

organismos internacionais (de caráter regional e universal).

\subsection{Nações Unidas}

Em março de 2020, as Nações Unidas publicaram um documento ressaltando a importância da solidariedade global e da responsabilidade compartilhada para responder aos impactos da pandemia de COVID-19².

Constatou-se que quase $30 \%$ dos trabalhadores em alguns dos setores econômicos mais afetados nos países da Organização para Cooperação e Desenvolvimento Econômico (OCDE) são imigrantes. Dessa forma, as perdas massivas de empregos entre os trabalhadores imigrantes gerarão um efeito dominó em economias que são fortemente dependentes de remessas monetárias ao exterior, tais como $\mathrm{El}$ Salvador, Haiti, Honduras, Nepal, Tonga, Tajiquistão e Quirguistão. Além disso, estima-se que os efeitos sejam ainda maiores em economias com setor informal de tamanho considerável, nas quais geralmente os sistemas de proteção social não existem ou são limitados, ou, ainda que haja a predominância do setor formal, este esteja mais suscetível à volatilidade do mercado (UNITED NATIONS, 2020a, p. 8).

As pessoas jovens, que representam um pouco mais de $30 \%$ do total de imigrantes e refugiados ao redor do mundo, estão mais suscetíveis a sofrer, de forma desproporcional, os efeitos negativos da pandemia e suas consequências, seja pela limitação do movimento nas fronteiras, diminuição das oportunidades de trabalho, aumento dos episódios de xenofobia, dentre outras (UNITED NATIONS, 2020a, p. 18).

Além disso, externou-se preocupação de que pessoas privadas da liberdade, confinadas em centros de detenção migratória, ou em instituições de saúde mental, são mais suscetíveis ao risco de contaminação pelo vírus, devido à própria natureza dessas instalações (UNITED NATIONS, 2020a, p. 8).

Os acampamentos de refugiados passam por problemas semelhantes, pois muitas vezes são obrigados a conviver em espaços superlotados, submetidos a precárias condições de higiene (UNITED NATIONS, 2020a, p. 8). Exemplos podem ser encontrados em todas as partes do globo, inclusive na Europa. Boaventura de Souza Santos escreve que, no campo de

\footnotetext{
Disponível em: https://unsdg.un.org/sites/default/files/202003/SG-Report-Socio-Economic-Impact-of-Covid19.pdf. Acesso em: 05 jun. 2020.
} 
internamento de refugiados e imigrantes de Moria, na Grécia, "há uma torneira de água para 1300 pessoas e falta sabão. Os internados não podem viver senão colados uns aos outros. Famílias de cinco ou seis pessoas dormem num espaço com menos de três metros quadrados" (SANTOS, 2020, p. 49).

Em outro documento, publicado em abril de $2020^{3}$, as Nações Unidas ressaltaram que os migrantes, refugiados e pessoas deslocadas internacionalmente, são particularmente mais suscetíveis ao estigma, à xenofobia, ao discurso de ódio e à intolerância. Os migrantes enfrentam problemas relacionados à perda de postos de trabalho, discriminação e dificuldade a retornarem ao país de origem, em razão do fechamento as fronteiras (2020b, p. 11).

Segundo dados apresentados, naquela altura, por volta de 167 países haviam determinado o fechamento de suas fronteiras. Além disso, 57 Estados impediram o acesso a procedimentos de solicitação de asilo. Desde que a crise começou, milhares de pessoas foram impedidas de cruzar a fronteira, devolvidas ao país de onde vieram, ou mesmo deportadas a ambientes hostis (UNITED NATIONS, 2020b, p. 11).

Ainda, constatou-se que os migrantes, apátridas, refugiados e pessoas deslocadas internacionalmente, foram, muitas vezes, excluídos das medidas de proteção, adotadas pelos Estados, no combate à pandemia de COVID19. Além disso, entendeu-se que muitos migrantes sem documentação deixaram de procurar os sistemas de saúde, por conta do medo de serem detidos ou deportados (UNITED NATIONS, 2020b, p. 11).

Portanto, em razão de todos esses problemas apresentados, ambos os documentos citados ressaltaram que as medidas de resposta aos impactos decorrentes da pandemia de COVID-19 devem ser pautadas pela proteção dos direitos humanos. Os esforços de preparação, resposta e recuperação devem ser orientados pela inclusão de vetores importantes, tais como idade, gênero e status migratório, para que todas as pessoas, particularmente as que se encontram em situação de maior vulnerabilidade, tenha suas necessidades básicas atendidas.

\subsubsection{Programa das Nações Unidas para o Desenvolvimento (UNDP)}

Em abril de 2020, o Programa das Nações Unidas para o Desenvolvimento (UNDP) publicou um documento sobre os impactos da pandemia de COVID-19, com enfoque na desigualdade de gênero ${ }^{4}$. O texto contém, também, algumas recomendações para aqueles responsáveis pelas formulações de políticas públicas.

Segundo os dados analisados, mulheres refugiadas se encontram em situação de maior vulnerabilidade, principalmente em contexto de mobilidade humana, devido ao risco de violência a que estão sujeitas durante o percurso da viagem. Além disso, constatou-se que as mulheres migrantes, particularmente aquelas envolvidas nos cuidados domésticos, estão mais suscetíveis, mais expostas, à contaminação pela COVID-19. Dessa forma, no contexto da crise sanitária, devido às mulheres migrantes e refugiadas se encontrarem em situação de particular vulnerabilidade, estão mais sujeitas à xenofobia, o que as tornam alvos fáceis para atos de violência e thes diminui as chances de encontrar empregos com remunerações e condições de trabalho justas (UNDP, 2020, p. 6).

De acordo com o relatório, a Organização das Nações Unidas para Alimentação e Agricultura reconheceu que a vulnerabilidade das mulheres à pobreza crônica, especialmente as residentes em áreas rurais e as indígenas, se deve à discriminação presente no ambiente de trabalho e à exclusão social, política e econômica. Deste modo, a afetação de padrões de consumo, causada pela pandemia de COVID-19, pode exacerbar o grau de vulnerabilidade das mulheres, em razão da diminuição da demanda por produtos agrícolas, o que reduz, por consequência, os rendimentos deles derivados. Além disso, a restrição à locomoção dificulta o desenvolvimento de atividades agrícolas e pecuárias, o que reflete negativamente na obtenção de recursos para manutenção familiar, de modo que o bem estar dessas mulheres e seus familiares fica comprometido (UNDP, 2020, p. 67).

De maneira similar, o texto ressalta que a Organização Internacional do Trabalho já fez vários alertas no sentido de que a crise de desemprego, advinda das medidas tomadas pelos

\footnotetext{
4 Disponível em:

https://www.undp.org/content/undp/en/home/librarypage/women s-empowerment/the-economic-impacts-of-covid-19-and-genderequality.html. Acesso em: 05 jun. 2020.
}

\footnotetext{
3 Disponível em: https://unsdg.un.org/resources/covid-19-andhuman-rights-we-are-all-together. Acesso em: 05 jun. 2020.
} 
países para combater a pandemia de COVID-19, poderia afetar, de maneira desproporcional, grupos específicos, de modo a exacerbar a desigualdade já existente. Dentre estes grupos, podem ser citados aqueles que não possuem garantia de emprego e são mal remunerados, as pessoas jovens, trabalhadores idosos, mulheres e imigrantes (UNDP, 2020, p. 7).

Para se tentar evitar todos esses impactos negativos da pandemia em relação aos grupos vulneráveis, deve-se proceder a uma gestão inclusiva e integrada da crise, especialmente no que tange às medidas de resposta. Com efeito, deve-se garantir que as pessoas migrantes tenham acesso a instalações seguras, especialmente nas fronteiras e comunidades anfitriãs vulneráveis, para o fim de se minimizar os riscos de contágio e situações de violência sexual ou baseadas em circunstâncias de gênero. Além disso, é importante se estender os programas extraordinários de garantia mínima de renda para todos os trabalhadores, inclusive os informais, eventuais, sazonais, migrantes ou autônomos (UNDP, 2020, p. 13-20).

\subsubsection{Comitê para Coordenação de Atividades Estatísticas (CCSA)}

O Comitê para Coordenação de Atividades Estatísticas (CCSA) elaborou um relatório que apresenta informações recentes sobre os impactos que a pandemia de COVID-19 está a causar pelo mundo ${ }^{5}$. Ao final de abril deste ano, 212 países, territórios ou áreas submetidas ao seu controle, haviam relatado casos de COVID19. Nos quatro primeiros meses deste ano, mais de 3 milhões de casos de contaminação e mais de 210 mil mortes foram confirmados (KOVACEVIC; JAHIC, 2020, p. 3).

Quando aos números econômicos, constatou-se uma queda de $9 \%$ na produção industrial, projetando-se uma queda de quase $27 \%$ no valor global do comércio de mercadorias para o segundo trimestre de 2020 , a maior queda de preços de matérias-primas já registrada até agora (KOVACEVIC; JAHIC, 2020, p. 3).

Quanto ao aspecto social, constatou-se o aumento do desemprego, pela diminuição de quase $10 \%$ do total de horas trabalhadas, o que equivale a 305 milhões de trabalhadores em tempo integral. Aproximadamente 1,6 bilhões de estudantes foram afetados pelo fechamento das

\footnotetext{
5 Disponível em: http://hdr.undp.org/en/content/how-covid-19changing-world-statistical-perspective. Acesso em: 05 jun. 2020.
}

escolas e a crise levará de 40 a 60 milhões de pessoas à extrema pobreza (KOVACEVIC; JAHIC, 2020, p. 3).

Quanto às medidas de restrição, em resposta à pandemia, mais de 100 países declararam estado de emergência, ou tomaram medidas de emergência para contenção do vírus. O Direito Internacional permite a adoção de medidas restritivas em resposta a ameaças significativas, porém, tais medidas, além de autorizadas por lei, devem ser proporcionais, necessárias, temporárias e não discriminatórias. Ressalta-se que os Estados partes do Pacto Internacional dos Direitos Civis e Políticos deveriam enviar notificações formais a respeito das medidas de emergência que implementaram ao Secretário Geral das Nações Unidas. Entretanto, de 9 de março a 15 de abril de 2020, somente 13 Estados o haviam feito (KOVACEVIC; JAHIC, 2020, p. 42).

Quanto à taxa de contaminação, considerando que a COVID-19 se dissemina mais rapidamente em áreas densamente povoadas, dados geoespaciais são de grande utilidade para se estimar a densidade populacional dos campos de refugiados, para o fim de se determinar quais locais estão sujeitos a maiores riscos. Somente a título de exemplo, o maior campo de refugiados do mundo se encontra na cidade de Cox's bazar, em Bangladesh. Com mais de 800 mil refugiados, o campo possui uma densidade populacional 1,5 vezes maior que a cidade de Nova York. Neste sentido, avaliações remotas de vulnerabilidade estão sendo realizadas pelo Alto Comissariado das Nações Unidas para os Refugiados (UNHCR) e seus parceiros (KOVACEVIC; JAHIC, 2020, p. 50).

Quanto às solicitações de refúgio, o UNHCR possui um sistema de registro de refugiados, atividade essencial desenvolvida pela sua equipe de campo. Em razão das medidas de restrição impostas pelos países, o desempenho de tal atividade continuou na medida do possível, seja remotamente, seja pelo agendamento das tarefas ao longo de grandes períodos de tempo (obedecendo-se, assim, as regras de distanciamento social). Entretanto, como consequência desse cenário, houve uma diminuição de $80 \%$ do número de refugiados registrados no sistema de gestão do UNHCR no período entre meados de fevereiro e meados de abril. As maiores reduções ocorreram nas regiões leste, meio-leste e meio-norte da África (KOVACEVIC; JAHIC, 2020, p. 51). 
Ainda segundo o relatório, o direito de buscar asilo também foi afetado pela pandemia, já que o acesso ao procedimento de regularização foi suspenso em vários países. Além disso, o andamento dos procedimentos já em curso também foram prejudicados, pois se constatou que as entrevistas com os solicitantes estão sendo adiadas, ou realizadas apenas em casos urgentes. Ao menos 73 países restringiram, de forma total ou parcial, o acesso a procedimentos de solicitação de asilo, sendo que 58 países não permitem acesso livre ao respectivo sistema nacional de registro. Dessa forma, estatísticas globais sobre asilo podem não representar a real magnitude de pessoas que buscam proteção internacional em tempos de pandemia (KOVACEVIC; JAHIC, 2020, p. 51).

\subsubsection{Organização Internacional para Migrações (IOM)}

A Organização Internacional para Migrações (IOM) também vem realizando um trabalho de análise dos impactos gerados pela crise sanitária do COVID-19 sobre os diferentes grupos especialmente vulneráveis de imigrantes, porém com maior enfoque em relação aos países e lugares mais drasticamente afetados pelos estágios iniciais da pandemia ${ }^{6}$, isto é, Estados Unidos da América e Europa. Com efeito, em razão da intensa movimentação de pessoas ao longo das rotas turísticas e comerciais, a COVID10 afetou, de início, os países vizinhos da China, considerada a origem do surto viral $(2020$, p. 3).

Quanto ao aceso aos serviços de saúde, constatou-se que, em vários países, os imigrantes, especialmente aqueles em situação irregular ou detentores de vistos válidos por curtos períodos, não usufruem do mesmo direito de acesso assegurado aos cidadãos, de modo que resta prejudicada a cobertura para tratamento da COVID-19, caso acabem por contrair a doença (IOM, 2020, p. 5).

Quanto às condições de vida, geralmente os imigrantes vivem em ambientes superlotados, sem o acesso adequado à agua e aos produtos de higiene pessoal. Nestes lugares, torna-se difícil cumprir as medidas de distanciamento social e outras práticas básicas de prevenção, tais como o isolamento em caso de enfermidade. Deste modo, as pessoas deslocadas, internamente ou através das fronteiras, estão sujeitas a um maior

\footnotetext{
6 Disponível em: https://publications.iom.int/books/mrs-no-60migrants-and-covid-19-pandemic-initial-analysis. Acesso em: 05 jun. 2020.
}

e concreto risco de contaminação (IOM, 2020, p. 6-7).

Quanto às condições de trabalho, as atividades laborais que são geralmente desempenhadas pelos imigrantes também os colocam em situação de maior exposição e vulnerabilidade. Com efeito, os imigrantes representam, em grande proporção, parte da mão de obra dos setores que permaneceram ativos durante a crise, tais como agricultura, construção civil, logística e entregas, provedor de cuidados pessoais e de saúde, coletores de lixo e serviços de limpeza (IOM, 2020, p. 7).

Quanto ao fluxo migratório, a maioria dos países, na tentativa de conter o avanço da COVID19 , procedeu ao fechamento das fronteiras e ao endurecimento dos regimes de imigração. Para tentar diminuir o fluxo migratório, os países estão a praticar condutas reprováveis, do ponto de vista dos direitos humanos. Com efeito, os imigrantes estão sendo obrigados a retornar de onde vieram, ou, caso consigam cruzar a fronteira, devem cumprir um período de quarentena, em instalações adaptadas e superlotadas, onde estão submetidos a todo tipo de ameaça à saúde, à dignidade e à própria sobrevivência (IOM, 2020, p. 9).

Quanto ao procedimento de regularização do status migratório, em alguns países, os imigrantes ainda são obrigados a seguir trâmites administrativos para regularização da situação migratória, seja para obtenção de visto, seja para sua renovação. Entretanto, dar andamento a tais procedimentos tornou-se um verdadeiro desafio, já que as autoridades competentes estão a limitar os horários de expediente, bem como suspender qualquer tipo de atendimento presencial. Além disso, os movimentos na fronteira estão cada vez mais restritos (IOM, 2020, p. 10).

Quanto ao comportamento da sociedade receptora, desde os estágios iniciais, a pandemia desencadeou incontáveis episódios de xenofobia, tanto em relação aos migrantes internos na China, quanto em relação aos imigrantes asiáticos em países ao redor do mundo. Progressivamente, tais episódios também se estenderam a imigrantes europeus e estrangeiros em geral, inclusive na China e em áreas apenas marginalmente afetadas pela COVID-19. Embora repreensíveis, a estigmatização (isto é, a recriminação por características pessoais) e a culpabilização (isto é, a procura por um culpado) são fenômenos de reação comuns nos períodos 
que se seguem a qualquer tipo de desastre, tais como catástrofes naturais, atos de terrorismo, pandemias e epidemias (IOM, 2020, p. 11).

\subsection{Centro de Migração Mista (MMC)}

0 Centro de Migração Mista ${ }^{7}$ (MMC) vem realizando estudos periódicos a respeito da situação dos refugiados e migrantes ao redor do mundo, com enfoque em dados coletados na Ásia, na América Latina e nas regiões norte e oeste da África, à luz das consequências causadas pela pandemia de COVID-19. Na terceira edição ${ }^{8}$, 2.110 pessoas foram entrevistadas entre os dias 6 de abril a 10 de maio de 2020: 126 na Ásia, 382 na América Latina, 957 no norte da África e 645 no oeste da África. Enquanto que nas regiões africanas os entrevistados eram provenientes de vários países, na América Latina somente venezuelanos foram entrevistados, ao passo que na Ásia somente afegãos foram entrevistados (2020, p. 1-2).

Constatou-se que a diminuição do acesso ao mercado de trabalho (que atinge $66 \%$ dos entrevistados) e a perda de rendimentos (que atinge $60 \%$ dos entrevistados) são os principais impactos gerados pela crise sanitária em relação a esse grupo de pessoas. Dentre estes, a maior porcentagem se encontra na América Latina (90\%) (MMC, 2020, p. 7). Importante destacar que a maioria desses imigrantes enviava dinheiro para seu país de origem, muitas vezes como forma de manutenção do núcleo familiar que lá permaneceu. Devido a esses problemas financeiros, mais de $51 \%$ dos entrevistados na América Latina afirmaram que não têm mais condições de continuar a fazer tais remessas (MMC, 2020, p. 1).

Quanto ao acesso à informação e à percepção de risco, constatou-se que a ampla maioria dos entrevistados tinha consciência sobre os perigos gerados pelo coronavirus. Somente três pessoas, entrevistadas na Líbia, afirmaram desconhecer sobre a COVID-19. Além disso, 47\% consideram o governo a principal e mais confiável fonte de informação sobre a doença. Este número, entretanto, sobe para $69 \%$ se

\footnotetext{
${ }^{7} \mathrm{O}$ Centro de Migração Mista (MMC) é a principal fonte para obtenção de informação independente, eficiente e de alta qualidade, pesquisa, análise e conhecimento especializado sobre migração mista. O MMC é parte do Conselho Dinamarquês para os Refugiados (DRC), sendo por este administrado. Disponível em: http://www.mixedmigration.org/. Acesso em: 05 jun. 2020.

Disponível em: https://reliefweb.int/report/world/mixedmigration-centre-covid-19-global-update-3-impact-covid-19refugees-and-migrants. Acesso em: 05 jun. 2020.
}

considerada apenas a América Latina. Em razão das informações recebidas, $90 \%$ dos entrevistados afirmaram que tomam as medidas necessárias para se proteger do risco de contaminação da doença, sendo comumente mais citadas a higienização mais frequente das mãos (76\%) e a utilização de máscara (59\%). Ainda, somente $2 \%$ dos entrevistados tiveram acesso a testes de detecção para o vírus: 5 na América Latina, 8 no norte da África, 23 no oeste da África e 0 testes na Ásia (MMC, 2020, p. 3-4).

Quanto à prevenção e ao acesso a cuidados básicos e intensivos, 38\% dos entrevistados acreditam que terão acesso ao sistema de saúde caso apresentem sintomas de COVID-19. Nos estudos anteriores a esta terceira edição, a falta de dinheiro (39\%), o desconhecimento de para onde se dirigir para obtenção de assistência médica (26\%) e discriminação contra estrangeiros (25\%) são relatadas como as principais barreiras de acesso ao sistema de saúde (MMC, 2020, p. 5).

Quanto à assistência social, a porcentagem de entrevistados que afirmaram necessitar de apoio adicional é de $87 \%$, com poucas e mínimas diferenças entre as regiões analisadas. Os assuntos mais citados foram: dinheiro (77\%), mais frequentemente citado nas regiões da África; necessidades básicas, tais como comida, água e abrigo (60\%), mais frequentemente citadas na América Latina; e itens sanitários, tais como higienizador de mãos e máscaras (44\%). Na Ásia, as necessidades de acesso ao sistema de saúde (51\%) e de assistência psicológica (28\%) foram mencionadas com mais frequência. Além disso, de uma maneira geral, somente $21 \%$ dos entrevistados afirmaram ter recebido apoio adicional desde o começo da crise gerada pela COVID-19. Destes, a maior porcentagem se encontra na América Latina (31\%) (MMC, 2020, p. 6).

\section{RESPOSTAS À COVID-19}

O Comitê Permanente Interagências da ONU $(\mathrm{IASC})^{9}$, em parceria com a Federação

\footnotetext{
9 A Assembleia Geral da ONU, ao aprovar a Resolução no 46/1824, de 19 de Dezembro de 1991, determinou a criação do Gabinete para Coordenação de Assuntos Humanitários ("Office for the Coordination of Humanitarian Affairs" - OCHA), do cargo de Coordenador de Ajuda Emergencial ("Emergency Relief Coordinator" - ERC), bem como dos mecanismos e ferramentas necessários para o bom desempenho de tal coordenação, tais como o Comitê Permanente Interagências ("Inter-Agency Standing Committee" - IASC), o Processo de Apelo Consolidado ("Consolidated Appeals Process" - CAP) e o Fundo Central Autorenovável de Emergência Humanitária ("Central Emergency
} 
Internacional das Sociedades da Cruz Vermelha e do Crescente Vermelho, com a Organização Internacional para Migrações, com o Alto Comissariado das Nações Unidas para os Refugiados e com a Organização Mundial da Saúde, publicou um documento, contendo diretrizes para elaboração de medidas de planejamento e resposta à pandemia de COVID19 , com vistas à assistência humanitária ${ }^{10}$.

Segundo o documento, pessoas afetadas por crises humanitárias, particularmente as deslocadas, internas e externas, bem como aquelas vivendo em campos de refugiados, estão sujeitas mais frequentemente à condição de vulnerabilidade, que deve ser levada em consideração quando do planejamento de operações de resposta à crise sanitária da COVID19. Essas pessoas frequentemente são negligenciadas, estigmatizadas e enfrentam dificuldades de acesso aos sistemas de saúde (que geralmente é garantido apenas aos nacionais dos respectivos países) (IASC, 2020, p. 2).

É de extrema importância, então, sob a perspectiva dos direitos humanos e de saúde pública, que todas as pessoas afetadas pelas crises humanitárias sejam incluídas nos planos estratégicos de resposta à pandemia de COVID19 , a despeito do status que ostentam, isto é, se nacionais ou estrangeiros, se em situação irregular ou regular (IASC, 2020, p. 2).

O Alto Comissariado das Nações Unidas para os Refugiados também publicou suas considerações em documento próprio ${ }^{11}$, por meio do qual reconhece que os Estados podem determinar medidas de controle sanitário e de saúde, tais como a imposição de quarentena, às pessoas que buscam proteção internacional. Porém, tais medidas não podem privá-las do direito de postular asilo ou resultar no refoulement. Com efeito, as ações estatais devem ser proporcionais, razoáveis, não discriminatórias e ter como objetivo único a proteção da saúde pública. Além disso, as pessoas que buscam proteção internacional devem ter acesso à

Revolving Fund" - CERF). Dessa forma, o IASC é um fórum interagências único para a coordenação, políticas de desenvolvimento e tomada de decisões envolvendo as Nações Unidas e outros parceiros humanitários.

10 Disponível em: https://interagencystandingcommittee.org/other/interim-guidancescaling-covid-19-outbreak-readiness-and-response-operationscamps-and-camp. Acesso em: 05 jun. 2020.

11 Disponível em: https://data2.unhcr.org/en/documents/details/75349. Acesso em: 05 jun. 2020. informação adequada, em línguas das quais tenham conhecimento, bem como a elas deve ser assegurado o direito de solicitar asilo perante autoridades competentes (2020, p. 1).

A perspectiva de proteção dos direitos humanos sempre foi mencionada, em todos os documentos elaborados pelas Nações Unidas, como vetor primordial no combate aos efeitos adversos gerados pela pandemia de COVID-19, no sentido de que todas as pessoas, particularmente as que se encontram em situação de maior vulnerabilidade, devem ter seus direitos garantidos.

Foi nesta toada que, no final de março de 2020, os presidentes de 10 Comitês, criados no âmbito dos Tratados Internacionais juridicamente vinculantes sobre Direitos Humanos das Nações Unidas, de forma conjunta ${ }^{12}$, exortaram aos lideres globais que adotem uma abordagem centrada nos direitos humanos, quando da elaboração de medidas para responder à ameaça que a crise sanitária representa à saúde pública. Com efeito, a pandemia somente pode ser combatida com sucesso, mediante a inclusão de todas as pessoas, sem distinção, nas estratégias e planos de resposta ${ }^{13}$.

Segundo a declaração, assinada pelos mencionados presidentes de 10 Comitês, os Estados devem ter um cuidado adicional em relação aos grupos particularmente mais vulneráveis aos efeitos da COVID-19, tais como pessoas idosas, pessoas com deficiência, minorias, pessoas indígenas, refugiados, postulantes de asilo e migrantes, pessoas privadas da liberdade, pessoas desabrigadas e pessoas vivendo na pobreza. Ressaltou-se, também, o risco desproporcional a que as mulheres estão sujeitas, devido ao fato de que, em muitas sociedades, são as principais

\footnotetext{
${ }^{12}$ A declaração foi subscrita pelos seguintes Comitês das Nações Unidas: Comitê de Direitos Humanos; Comitê sobre Direitos Econômicos, Sociais e Culturais; Comitê para a Eliminação da Discriminação Racial; Comitê sobre os Direitos das Pessoas com Deficiências; Comitê dos Direitos das Crianças; Comitê para Eliminação da Discriminação contra a Mulher; Comitê contra a Tortura e seu Subcomitê para Prevenção da Tortura; Comitê contra Desaparecimentos Forçados; e Comitê sobre os Trabalhadores Migrantes. Cada um desses Comitês foi criado no âmbito de um Tratado Internacional de Direitos Humanos das Nações Unidas. São compostos por especialistas independentes (da influência direta dos Estados), que visam assegurar que os Estados-parte cumpram as obrigações legais previstas em tais documentos juridicamente vinculativos.

${ }_{13}$ Disponível em:

https://www.ohchr.org/en/NewsEvents/Pages/DisplayNews.aspx?N ewsID=25742\&LangID=E. Acesso em: 05 jun. 2020.
} 
responsáveis pelos cuidados dos membros familiares doentes (2020, n.p.).

Importante ressaltar que, além da referida declaração conjunta, também foram elaborados documentos próprios por parte de alguns Comitês das Nações Unidas, no respectivo âmbito de atuação ${ }^{14}$. Somente a título de exemplo, citam-se, aqui, as diretrizes publicadas pelo Comitê dos Direitos das Crianças (CRC), no começo de abril de $2020^{15}$. Ao todo, foram apresentadas 11 recomendações aos Estados.

De acordo com o documento, há crianças cuja vulnerabilidade se tornou ainda mais evidente e acentuada em razão das circunstâncias geradas pela pandemia de COVID19 , tais como as crianças em situação de rua, migrantes, postulantes de asilo, refugiadas, deslocadas internamente, indígenas, privadas de liberdade (como aquelas detidas em centros de detenção migratória), dentre outras. Por esta razão, os Estados têm o dever de incluir todas elas nos planos de resposta à crise sanitária, com base no postulado da não discriminação. Além disso, as crianças em situação de migração não devem ser detidas, nem mesmo separadas de seus pais ou responsáveis, caso acompanhadas. Por fim, ainda em relação às crianças migrantes, o acesso à informação sobre as formas de prevenção da doença deve ser adequado, veiculado em formato e linguagem acessível e de fácil compreensão (CRC, 2020, p. 2-3).

\subsection{União Europeia}

A União Europeia publicou um boletim sobre as implicações geradas pela pandemia de COVID-19 sobre os direitos humanos fundamentais, com enfoque nas medidas tomadas pelos governos de seus Estados membros, tomando-se em consideração o período compreendido entre 10 de fevereiro a 20 de março de 2020, para o fim de se tentar obter uma resposta conjunta, baseada nas melhores práticas, à luz da Carta dos Direitos Fundamentais

\footnotetext{
14 Tais instrumentos, compostos por recomendações, diretrizes, declarações, comunicados de imprensa, dentre outros, foram compilados, pelo Alto Comissariado das Nações Unidas para os Direitos Humanos, num único documento, que foi revisto, pela última vez, em 19 de junho de 2020. Disponível em: https://www.ohchr.org/Documents/HRBodies/TB/COVID19/Externa I_TB_statements_COVID-19_19jun20.pdf. Acesso em: 02 jul. 2020. Disponível em: https://tbinternet.ohchr.org/_layouts/15/treatybodyexternal/Down load.aspx?symbolno=INT/CRC/STA/9095\&Lang=en. Acesso em: 05 jun. 2020.
}

da União Europeia ${ }^{16}$. O documento reconhece que a população europeia não é homogênea, de modo que certos indivíduos e grupos são particularmente mais suscetíveis à crise humanitária, principalmente pela situação socioeconômica a que estão sujeitos. Aqui se incluem as pessoas mais velhas, os ciganos, os imigrantes, os solicitantes de asilo e refúgio, pessoas com deficiências, dentre outras (2020, p. $5)$.

O boletim aborda quarto assuntos interrelacionados: 1) medidas para conter a pandemia de COVID-19 e mitigar seus impactos nas seguintes áreas: convivência social, educação, trabalho e liberdade de locomoção, bem como asilo e imigração; 2) os impactos gerados pelo vírus e os esforços para evitar e limitar a sua disseminação em relação a grupos específicos da sociedade; 3) incidentes de xenofobia e discriminação racial, inclusive crimes de ódio; 4) a propagação de desinformação relacionada à pandemia e as implicações geradas por eventuais medidas de controle sobre proteção de dados e privacidade (EUROPEAN UNION, 2020, p. 7).

Quanto aos impactos gerados pelo vírus em relação a grupos específicos da sociedade, os Estados membros estabeleceram medidas especiais de prevenção e mitigação nos ambientes institucionais, tais como prisões, unidades residenciais de cuidado, campos de refugiados/instalações de acolhimento e abrigos, onde o risco de infecção é maior devido à dificuldade de se implementar medidas de distanciamento. A esse respeito, em razão do evidente risco de infecção, no dia 31 de março de 2020, quatro organizações da ONU recomendaram a libertação dos refugiados e imigrantes mantidos em lugares formais e informais de detenção. Dessa forma, em 26 de março de 2020, o Conselho Europeu exortou aos Estados Membros que libertassem os imigrantes em situação irregulares, inclusive aqueles cuja solicitação de asilo foi rejeitada, mantidos em estabelecimentos de detenção migratória que não poderiam ser enviados ao país de origem, devido à suspensão dos procedimentos de retorno, em razão do contexto da pandemia de COVID-19. Nesta toada, organizações de apoio aos imigrantes, na Irlanda, expressaram preocupação sobre as condições das instalações de acolhimento, alertando que os impactos da

Disponível em:
https://fra.europa.eu/en/publication/2020/covid19-rights-impactapril-1. Acesso em: 05 jun. 2020. 
pandemia seriam devastadores, devido à impossibilidade de autoisolamento e distanciamento social. Na Alemanha, o Conselho Bávaro para refugiados solicitou a imediata dissolução dos alojamentos localizados nos centros de refugiados, em razão do risco de infecção, tendo proposto que as pessoas deveriam ser alocadas em apartamentos ou hotéis (EUROPEAN UNION, 2020, p. 10; 29).

Quanto ao acesso a educação, constatouse que crianças provenientes de grupos desfavorecidos têm menor probabilidade de conseguir acesso a computadores, equipamentos digitais ou mesmo internet, para continuidade do ensino de forma remota. Em alguns países, como o Chipre, professores relataram que tiveram problemas em manter contato com as famílias de imigrantes e refugiados. Há, também, relatos, da Bulgária e da Grécia, de suspensão do ensino e dos grupos de atividades nos centros de refugiados. Por outro lado, na Croácia, o governo implantou medidas para que as crianças, nos centros de acolhimento, possam seguir os programas escolares transmitidos pela televisão (EUROPEAN UNION, 2020, p. 18).

Quanto ao movimento nas fronteiras, o Alto Comissariado das Nações Unidas para os Refugiados já havia estabelecido diretrizes para que as restrições fossem implementadas de acordo com o princípio do non-refoulement. Entretanto, alguns Estados membros da União Europeia baniram a entrada para os solicitantes de asilo, atitude contrária ao que dispõe o artigo 18 (direito ao asilo) e 19 (proteção contra o refoulement) da Carta dos Direitos Fundamentais da União Europeia. A esse respeito, foram apresentados três exemplos: 1) em 20 de março de 2020, a guarda costeira do Chipre forçou o retorno de uma embarcação com aproximadamente 175 sírios a bordo, sendo 30 mulheres e 69 crianças, que postulariam asilo em território europeu; 2) a Hungria suspendeu a admissão de postulantes de asilo nas zonas de trânsito, na fronteira com a Sérvia, devido ao risco relacionado com a COVID-19; e 3) a Grécia suspendeu temporariamente acesso à solicitação de asilo desde março de 2020, enquanto os imigrantes e refugiados se amontoavam em grandes números na fronteira com a Turquia. Por outro lado, outros Estados membros preferiram uma abordagem mais flexível. A Áustria, por exemplo, exige que os solicitantes de asilo e refúgio, que cheguem pela via aérea, mostrem evidência de teste negativo para COVID-19, de preferência obtido há não mais do que 4 dias, para que possam adentrar ao território, caso contrario são colocam em uma instalação para cumprimento de quarentena de duas semanas (EUROPEAN UNION, 2020, p. 24).

Quanto ao acesso à informação, há relatos promissores a respeito de medidas de conscientização sobre a COVID-19 aos residentes de centros de acolhimento de refugiados e solicitantes de asilo. Por exemplo, em Portugal, o Conselho para Refugiados organizou sessões informativas, emitiu recomendações em várias línguas, afixou cartazes com diretrizes de prevenção e distribuiu kits contendo álcool em gel e desinfetantes. Por sua vez, o Alto Comissariado das Nações Unidas para os Refugiados em Malta produziu um documento escrito em várias línguas e estabeleceu um grupo de facebook (EUROPEAN UNION, 2020, p. 29).

\subsection{América}

No mês de abril de 2020, a Secretaria Geral da Organização dos Estados Americanos (SGOEA) publicou um guia prático para orientação de respostas inclusivas a serem implementadas por ocasião da pandemia de COVID-19, com enfoque em direitos humanos ${ }^{17}$. Justificou-se a elaboração do documento pela importância que a perspectiva de direitos humanos deve exercer sobre as medidas de combate à crise sanitária, especialmente em relação aos grupos em situação de mais acentuada vulnerabilidade, que, em razão de discriminação múltipla e interseccional a que estão sujeitos, que se agrava em tempos pandemia, encontram maiores dificuldades de acesso às políticas de prevenção, mitigação e atenção aos cuidados de saúde $(2020$, p. 8).

Os grupos em situação de vulnerabilidade são todos aqueles que, por motivo de raça, cor, linguagem, origem nacional ou étnica, identidade cultural, religião, idade, sexo, orientação sexual, identidade e expressão de gênero, condição migratória, refugiado, repatriado, apátrida ou deslocado interno, deficiente, ou quaisquer outras características biopsicossociais, sofrem discriminação e têm seus direitos negados ou violados em razão dessas características. Enquadram-se, aqui, as pessoas pobres e marginalizadas, tais como os povos indígenas, afrodescendentes, pessoas com deficiência,

\begin{tabular}{l}
\hline 17 \\
http://www.oas.org/es/sadye/publicaciones/GUIA_SPA.pdf. Acesso \\
em: 05 jun. 2020.
\end{tabular}


migrantes, refugiados, pessoas LGBTI, crianças, adolescentes, mulheres e idosos (SGOEA, 2020, p. 9).

O documento traz 4 princípios que devem guiar a ação dos países na formulação de medidas inclusivas de proteção dos direitos humanos dos grupos vulneráveis: 1) igualdade e não discriminação, extremamente necessários em um contexto regional marcado pela desigualdade e exclusão social; 2) disponibilidade de bens, serviços e espaços; 3 ) acessibilidade física, de informação e comunicação, de mobilidade, econômica (poder de compra), de infraestrutura, dentre outras; 4) aceitação: consentimento livre e informado, resguardo da ética, do respeito à integridade humana e aos fatores culturais, linguísticos, de gênero, biopsicossociais e de idade (SGOEA, 2020, p. 9).

Além disso, o guia também elenca uma série de instrumentos jurídicos de proteção de direitos humanos que devem ser observados pelos países da região, para o fim de se garantir o pleno gozo do direito à saúde, bem como a proteção de todas as facetas dos direitos das pessoas no contexto da atual pandemia. São eles: 1) a Declaração Americana dos Direitos e Deveres do Homem, de 1948, que em seu artigo XI garante o direito à preservação da saúde e do bem estar; 2) a Convenção Americana de Direitos Humanos, de 1969, também conhecida como Pacto de San José da Costa Rica, que atribui, aos Estados partes, o dever de garantir direitos, bem como as condições básicas para o exercício destes, a todas as pessoas, sem distinção, tais como a preservação da saúde e do acesso igualitário aos serviços essenciais, à proteção social, ao trabalho, à vida, dentre outros; 3) o Protocolo Adicional à Convenção Americana de Direitos Humanos, em matéria de Direitos Econômicos, Sociais e Culturais, de 1988, também conhecido como protocolo de San Salvador, que aborda diretamente o direito à saúde, a nível físico, mental e social, bem como impõe aos Estados signatários a obrigação de reconhecer a saúde como um bem público e adotar as medidas necessárias para que tal direito seja garantido a todas as pessoas sujeitas à jurisdição estatal. Dentre estas, podem ser citadas a total imunização contra as principais doenças infecciosas, a prevenção e o tratamento das doenças endêmicas, bem como o atendimento prioritário das necessidades de saúde dos grupos de risco e que, por suas condições de pobreza, sejam mais vulneráveis; 4) a Carta Social das
Américas e seu Plano de Ação, que, embora seja considerada um compromisso político (e não propriamente jurídico), reafirma que a fruição do mais alto nível de saúde é um dos direitos fundamentais de todo ser humano, que deve ser garantido sem qualquer tipo de discriminação (SGOEA, 2020, p. 11-12).

Para a apresentação das recomendações a serem tomadas pelos países, em contexto da pandemia de COVID-19, o documento é dividido em 10 capítulos: 1$)$ o primeiro relacionado às mulheres e às questões de gênero; 2 ) o segundo relacionado aos idosos; 3 ) o terceiro relacionado às pessoas com deficiência; 4) o quarto relacionado com a população afrodescendente; 5) o quinto relacionado aos povos indígenas; 6$)$ o sexto relacionado às pessoas LGBTIQ; 7) o sétimo relacionado aos deslocados internos, migrantes, solicitantes de asilo e refugiados; 8) o oitavo relacionado às pessoas privadas da liberdade; 9 ) o nono relacionado às pessoas em situação de pobreza e pobreza extrema; 10) o décimo relacionado à infância, educação e assistência social.

Especificamente em relação ao capítulo VII, importante considerar que as pessoas imigrantes e refugiadas são especialmente vulneráveis à pandemia de COVID-19, pois muitas delas encontram enorme dificuldade de acesso a condições sanitárias adequadas e programas de saúde, devido à sua nacionalidade ou condição migratória. Além disso, enfrentam desafios para cumprir as medidas de distanciamento social, em razão da superlotação dos locais em que vivem, ou pela necessidade de trabalhar no mercado informal, que, assim como acontece na Europa, é um setor que ainda permanece ativo durante a crise (SGOEA, 2020, p. 55-56).

Em relação a esse grupo específico de pessoas, há também instrumentos jurídicos adicionais de proteção de direitos humanos que devem ser observados pelos países da região: 1 ) os Princípios Interamericanos sobre os Direitos Humanos de todas as pessoas migrantes, refugiadas, apátridas e vítimas do tráfico de pessoas, de 2019, que têm a finalidade de orientar os Estados Membros da OEA no cumprimento de seus deveres de respeitar, proteger, promover e garantir os direitos humanos de todas as pessoas, independentemente de nacionalidade ou situação migratória; 2) a Convenção sobre o Estatuto dos Refugiados, de 1951, bem como o Protocolo sobre o Estatuto dos Refugiados e a 
Declaração de Cartagena sobre Refugiados, de 1984; 3) o Direito Internacional dos Apátridas, que inclui a Convenção sobre o Estatuto dos Apátridas, de 1960, e a Convenção destinada a reduzir os casos de Apatridia, de 1961, bem como os Princípios Orientadores relativos aos Deslocados Internos, de 1998 (SGOEA, 2020, p. 57).

Por fim, foram elaboradas varias recomendações, no sentido de contribuir para o desenvolvimento de políticas públicas e medidas de resposta que os Estados devem adotar frente aos impactos diretos e indiretos que a COVID-19 gera em relação às pessoas migrantes, solicitantes de asilo, refugiados deportados e repatriados, bem como às comunidades que os acolhem. Por óbvio que não serão todas aqui elencadas, mas, a título de exemplo, podem ser citadas: 1) garantir que as pessoas que solicitam proteção internacional possam adentrar ao território do país que buscam proteção, assim como assegurar o direito de solicitar e receber asilo, observar o princípio da não repulsão, incluindo-se, aqui, a proibição de recusa de entrada na fronteira; 2) assegurar a continuidade dos procedimentos de reconhecimento da condição de refugiado, no estrito cumprimento da garantia do devido processo, de modo a evitar atrasos excessivos, bem como implementar outros meios, distintos dos presenciais, para o cumprimento das diferentes etapas do procedimento, desde que tais medidas não afetem, de maneira desproporcional, os direitos das pessoas solicitantes de asilo; 3 ) garantir o direito de toda pessoa, especialmente aquelas em situação de vulnerabilidade mais acentuada, a regressar ao seu país de nacionalidade, respeitando-se as normas sanitárias internacionais e as diretrizes de proteção, segurança, acesso à informação, saúde e assistência emitida pelas autoridades nacionais de cada Estado; 4) promover a integração das pessoas migrantes e refugiadas nos planos nacionais, criados pelos Estados, para prevenir e combater a pandemia de COVID-19, de tal forma que Ihes seja garantida proteção, bem como às respectivas comunidades de acolhimento; 5) incluir as pessoas migrantes nos programas sociais, especialmente aquelas que não têm acesso à proteção social ou à licença remunerada em razão de doenças, para que sejam beneficiadas por ajudas econômicas temporárias, dentro do limite das capacidades dos Estados (SGOEA, 2020, p. 57-58). Como última observação, exorta-se aos Estados que as medidas tomadas somente farão frente à crise mundial sanitária se estiverem baseadas no multilateralismo, na cooperação internacional e na solidariedade (SGOEA, 2020, p. 59).

Ainda em relação ao continente americano, a Comissão Interamericana de Direitos Humanos (CIDH), com apoio de suas Relatorias especiais sobre os direitos econômicos, sociais, culturais, ambientais e sobre liberdade de expressão, adotou a Resolução no 1, de 10 de abril de 2020, de modo a alertar aos Estados que as medidas de prevenção, contenção e combate ao vírus devem observar o pleno respeito aos direitos humanos ${ }^{18}$. Com efeito, trata-se de uma região extremamente desigual, caracterizada por problemas transversais que afetam um grande número de pessoas em todos os Estados, tais como a pobreza extrema, a falta ou precariedade ao acesso à agua potável e ao saneamento básico, as situações de contaminação ambiental, as altas taxas de informalidade laboral, dentre outros. Esse cenário de exclusão social impede que milhões de pessoas, em particular aquelas submetidas a situações de especial vulnerabilidade, tenham acesso a medidas básicas de prevenção contra a pandemia de COVID-19 (2020, p. 3).

A Resolução editada é dividida em três partes. Em primeiro lugar, a Parte A - Introdução, na qual a Comissão Interamericana de Direitos Humanos apresenta um panorama geral sobre a situação de exclusão social das Américas, a fim de demonstrar a importância do respeito aos direitos humanos na elaboração das medidas de prevenção e contenção dos efeitos derivados da pandemia (CIDH, 2020, p. 3-4).

Em segundo lugar, a Parte B Considerativa, que apresenta a fundamentação jurídica do documento, composta por quatro tópicos: I) considerações sobre o direito à saúde, bem como sobre os direitos econômicos, sociais, culturais, ambientais e sobre liberdade de expressão, em contexto de pandemia; II) apontamentos sobre estados de exceção, liberdades fundamentais e Estado de Direito; III) menção a perspectivas interseccionais que devem nortear as medidas a serem tomadas em caso de grupos em situação de especial vulnerabilidade; IV) destaque à cooperação internacional e ao intercambio de boas práticas

\footnotetext{
${ }^{18}$ Disponível em: http://oas.org/es/cidh/decisiones/pdf/Resolucion1-20-es.pdf. Acesso em: 05 jun. 2020.
} 
como forma de superar, de forma mais exitosa, os desafios advindos da crise (CIDH, 2020, p. 5-8).

Em terceiro lugar, a Parte $\mathrm{C}$ - Resolutiva, que contém as recomendações aos governos dos Estados, para fins de proteção dos direitos humanos frente aos riscos advindos da pandemia de COVID-19. Inicialmente, foram apresentadas recomendações gerais. Há, também, entretanto, recomendações específicas, especialmente no que tange: I) aos direitos econômicos, sociais, culturais e ambientais; II) à restrição das liberdades fundamentais em situações de estado de exceção decretado pelos Estados; III) à proteção dos grupos em especial situação de vulnerabilidade, tais como as pessoas idosas, as pessoas privadas de sua liberdade, as mulheres, os povos indígenas, as pessoas migrantes, solicitantes de asilo, refugiadas, apátridas, vítimas de tráfico de pessoas e deslocadas internas, crianças e adolescentes, pessoas LGBTI, pessoas afrodescendentes e pessoas com deficiência (CIDH, 2020, p. 8-22).

Especificamente em relação às pessoas migrantes, solicitantes de asilo, refugiadas, apátridas, vítimas de tráfico de pessoas e deslocadas internas, foram editadas cinco recomendações: 1) evitar o emprego de estratégias de detenção migratória e outras medidas que possam aumentar os riscos de contaminação e propagação da COVID-19, ou mesmo que possam acentuar a vulnerabilidade de pessoas em situação de mobilidade humana, tais como deportações, expulsões coletivas, ou qualquer outra forma de repatriamento, executadas sem a devida observância das condições sanitárias necessárias à garantia de seus direitos. Além disso, implementar mecanismos de libertação das pessoas que atualmente se encontram em centros de detenção; 2) abster-se de implementar medidas que possam obstar, intimidar e desestimular o acesso das pessoas em situação de mobilidade humana aos programas, serviços e políticas de resposta e cuidados ante à pandemia de COVID19, tais como endurecimento do controle migratório ou repressão nas proximidades de hospitais ou albergues; 3 ) garantir o direito de regresso e a migração de retorno aos Estados (e territórios) de origem ou de nacionalidade, por meio de projetos de cooperação, intercâmbio de informação e apoio logístico entre os Estados envolvidos, com atenção aos protocolos sanitários aplicáveis. Além disso, também deve ser assegurado, às pessoas apátridas, o direito de retornar aos países em que mantêm residência habitual. Em todos os casos, deve ser observado o princípio da unidade familiar; 4) implementar medidas para evitar e combater a xenofobia e a estigmatização das pessoas em situação de mobilidade, especialmente por meio de projetos e campanhas de sensibilização, bem como elaboração de protocolos e procedimentos específicos de proteção e cuidados dirigidos a crianças e adolescentes migrantes e refugiados, especialmente em relação a aqueles que se encontram separados de seus responsáveis ou desacompanhados; 5) incluir, expressamente, as pessoas em situação de mobilidade nas políticas, ações e projetos de recuperação econômica que se façam necessárias em todos os momentos da crise geradas pela pandemia (CIDH, 2020, p. 1819).

\subsection{Organização Mundial da Saúde}

No mês de abril de 2020, a Organização Mundial da Saúde (WHO) publicou um comentário, na revista científica "The Lancet", a respeito das medidas de saúde a serem tomadas em resposta à pandemia de COVID-19 em relação aos refugiados e migrantes ${ }^{19}$. Segundo o texto, até 29 de março de 2020, houve relatos de casos de transmissão local de COVID-19 em 146 países e territórios, muitos deles anfitriões de grande quantidade de refugiados. Evidências mostram que este grupo de pessoas, embora tenham poucas chances de transmitir doenças à comunidade anfitriã quando cruzam as fronteiras, estão cada vez mais expostas a doenças e infecções, inclusive pela COVID-19, porque essas pessoas geralmente são colocadas em locais superlotados, sem acesso a comodidades básicas, tais como saneamento básico, água corrente e sabão, cuidados médicos insuficientes, acesso precário a informações adequadas sobre a doença, dentre outras. Dessa forma, os planos de resposta à crise sanitária também deve levar em consideração as necessidades dos migrantes e refugiados (KLUGE et al., 2020, p. 1238-1239).

Além disso, também no mês de abril de 2020, a Organização Mundial da Saúde publicou um documento, contendo orientações provisórias sobre medidas de preparação, prevenção e controle da doença causada pela COVID-19 em relação a refugiados e imigrantes que já não

\footnotetext{
$19 \quad$ Disponível

https://www.thelancet.com/pdfs/journals/lancet/PIIS01406736(20)30791-1.pdf. Acesso em: 05 jun. 2020.
}

em: 
vivem mais em instalações de acolhimento ${ }^{20}$. Com efeito, pelo fato de residir em acomodações individuais ou comunitárias nas cidades e áreas urbanas, eles enfrentam ameaças sanitárias e de saúde similares à população que os recebeu. Entretanto, devido às limitadas oportunidades de trabalho, precárias condições de trabalho, inadequado acesso à comida, água, saneamento básico e outros serviços básicos, os refugiados e imigrantes tornam-se ainda mais vulneráveis em vários aspectos (2020, p. 1).

Dessa forma, o objetivo da Organização Mundial da Saúde foi oferecer um norte de ação para os países, para o fim de contribuir com os esforços globais de prevenção aos riscos decorrentes da COVID-19, principalmente exortando aos Estados que procedam à inclusão dos imigrantes e refugiados nos planos de resposta à pandemia que são oferecidos à população em geral, isto é, aos seus próprios nacionais. Em tempos como esse, faz-se necessário o cumprimento e a obediência às obrigações assumidas no plano internacional com relação à proteção dos direitos humanos (WHO, 2020, p. 1).

O documento traz 6 princípios que devem guiar a ação dos países na proteção dos direitos humanos dos imigrantes e refugiados: 1) 0 direito a usufruir do mais elevado nível de saúde física e mental; 2) Acesso igualitário a serviços de saúde e não discriminação; 3) Sistemas de saúde baseados nas características específicas dos imigrantes e refugiados, tais como o gênero; 4) Tratamento igualitário no ambiente de trabalho; 5) Abordagem holística da sociedade como um todo na formulação das políticas governamentais; 6) Participação e inclusão social dos refugiados e imigrantes (WHO, 2020, p. 1-2).

Ao final, o documento formula 23 recomendações aos países: 1 ) Revisão dos planos nacionais de preparação e resposta a emergências, incluídas aqui a causada pela COVID19, do arcabouço jurídico e das exigências regulatórias, para o fim de garantir acesso a serviços de saúde aos refugiados e imigrantes; 2 ) Identificar e mapear instalações de saúde e isolamento disponíveis para os refugiados e imigrantes; 3) Tomar as medidas necessárias para se alcançar cobertura universal dos cuidados de saúde, para que os refugiados e imigrantes

\footnotetext{
$20 \quad$ Disponível em: https://apps.who.int/iris/rest/bitstreams/1275039/retrieve. Acesso em: 05 jun. 2020
}

também possam ser beneficiados; dentre outras (WHO, 2020, p. 2-4).

\section{CONCLUSÃO}

Os migrantes e refugiados já se encontram, comumente, em situações de vulnerabilidade. Durante esse período de pandemia de COVID-19, a vulnerabilidade desses grupos de pessoas se acentuou, seja pelos comportamentos de exclusão da sociedade em que estão inseridos, seja pelas medidas tomadas pelos governos para contenção dos impactos da doença, bem como mitigação dos seus efeitos.

Há relatos de que os índices de discriminação e xenofobia aumentaram durante este período pandêmico. Além disso, o exercício dos direitos humanos básicos também foi severamente comprometido, nos mais variados aspectos. Considerando que a maioria se submete a trabalhos informais, as medidas de isolamento social (e paralização de atividades do setor econômico), impostas pela maioria dos países, geraram reflexos negativos nos rendimentos dessas pessoas. Além disso, nos países em que o sistema de saúde não é universal, viram-se desprovidos do acesso aos cuidados básicos de saúde e higiene, tornando-se ainda mais suscetíveis não somente de contrair, mas também de propagar o vírus. Dessa forma, sem acesso ao sistema da previdência social, em razão da informalidade, e sem acesso ao sistema de saúde, restam poucas alternativas para manutenção de condições mínimas de sobrevivência.

A situação dos campos de refugiados também é preocupante. O confinamento de várias pessoas, num mesmo local, cujo número muitas vezes excede à capacidade de ocupação, somado às precárias condições de saúde, higiene e saneamento básico, facilita a propagação do vírus, tornando-se alvos fáceis da doença.

Diante deste cenário perturbador, vários órgãos e organismos, de amplitude regional e internacional, de caráter administrativo, legislativo e jurisdicional, apresentaram diretrizes a serem observadas e implementadas, no âmbito doméstico dos países, para o fim de se garantir direitos humanos básicos aos migrantes, refugiados e apátridas. Com efeito, à medida que a situação de vulnerabilidade se agrava, por conta da evolução da pandemia, tão mais eficazes devem ser as respostas a serem dadas pelos governos nacionais para garantia dos direitos humanos a esse grupo de pessoas. 


\section{REFERÊNCIAS}

CIDH. Comisión Interamericana de Derechos Humanos. Pandemia y Derechos Humanos en las Américas. Resolución no 1/2020. Espanha, 2020. Disponível em: http://oas.org/es/cidh/decisiones/pdf/Resolucio n-1-20-es.pdf. Acesso em: 05 jun. 2020.

CRC. Committee on the Rights of the Child. The Committee on the Rights of the Child warns of the grave physical, emotional and psychological effect of the COVID-19 pandemic on children and calls on States to protect the rights of children. April 2020. Disponível em: https://tbinternet.ohchr.org/_layouts/15/treatyb odyexternal/Download.aspx?symbolno=INT/CRC/ STA/9095\&Lang=en. Acesso em: 05 jun. 2020.

EUROPEAN UNION. European Union Agency for Fundamental Rights. Coronavirus Pandemic in the EU - Fundamental Rights Implications.

Bulletin \#1. 8 april. Luxembourg: Publications Office of the European Union, 2020. Disponível em:

https://fra.europa.eu/en/publication/2020/covid 19-rights-impact-april-1. Acesso em: 05 jun. 2020.

IASC. Inter-Agency Standing Committee. Interim Guidance: Scaling-up Covid-19 Outbreak Readiness and Response Operations in Humanitarian Situations - Including Camps And Camp-Like Settings. Estados Unidos: IFRC, IOM, UNHCR, WHO, 2020. Disponível em:

https://interagencystandingcommittee.org/other /interim-guidance-scaling-covid-19-outbreakreadiness-and-response-operations-camps-andcamp. Acesso em: 05 jun. 2020.

IOM. International Organization for Migration. Migrants and the COVID-19 pandemic: an initial analysis.Switzerland, 2020. n.60. Disponível em: https://publications.iom.int/books/mrs-no-60migrants-and-covid-19-pandemic-initial-analysis. Acesso em: 05 jun. 2020.

KLUGE, H. H. P. et al. Refugee and migrant health in the COVID-19 response. The Lancet, v. 395, Issue 10232, apr. p. 1237-1239, 2020. Disponível em:

https://www.thelancet.com/pdfs/journals/lancet /PIIS0140-6736(20)30791-1.pdf. Acesso em: 05 jun. 2020. DOI: https://doi.org/10.1016/S01406736(20)30791-1

KOVACEVIC, M. ; JAHIC, A. How COVID-19 is changing the world: a statistical perspective. Canadá: UNDP, 2020. Disponível em: http://hdr.undp.org/en/content/how-covid-19changing-world-statistical-perspective. Acesso em: 05 jun. 2020.

MMC. MIXED MIGRATION CENTER. Impact of COVID-19 on Refugees and Migrants. COVID-19 global update \#3 , 2020. Disponível em: https://reliefweb.int/report/world/mixedmigration-centre-covid-19-global-update-3impact-covid-19-refugees-and-migrants. Acesso em: 05 jun. 2020.

OHCHR. Office of the United Nations High Commissioner for Human Rights. Human Rights Treaty Branch: Compilation of statements by human rights treaty bodies in the context of COVID-19. Geneva, 2020. Disponível em: https://www.ohchr.org/Documents/HRBodies/TB /COVID19/External_TB_statements_COVID19_19jun20.pdf. Acesso em: 02 jul. 2020.

SANTOS, B. S. Vírus: Tudo o que é Sólido Desmancha no Ar. In: MELO FILHO, A. T. H. Quarentena: reflexões sobre a pandemia e depois. 1.ed. Bauru: Canal 6, 2020, p. 45-50.

SGOEA. Secretaría General de la Organización de los Estados Americanos y Organización de los Estados Americanos. Secretaría de Acceso a Derechos y Equidad (SARE). Guía Práctica de Respuestas Inclusivas y con Enfoque de Derechos ante el COVID-19 en las Américas. Abr. 2020. Disponível em: http://www.oas.org/es/sadye/publicaciones/GUI A_SPA.pdf. Acesso em: 05 jun. 2020.

THE LANCET. Redefining vulnerability in the era of COVID-19, v. 395, n. 10235, maio, 2020, p. 1089.

UNDP. United Nations Development Program. Briefing Note: The Economic Impacts of Covid-19 and Gender Inequality- Recommendations For Policymakers. Panamá: UNDP, 2020. Disponível em:

https://www.undp.org/content/undp/en/home/li brarypage/womens-empowerment/the- 
economic-impacts-of-covid-19-and-genderequality.html. Acesso em: 05 jun. 2020.

UNHCR. United Nations High Commissioner for Refugees. Key Legal Considerations on access to territory for persons in need of international protection in the context of the COVID-19 response. 2020.

Disponível em:

https://data2.unhcr.org/en/documents/details/7 5349. Acesso em: 05 jun. 2020.

UNHR. Office of the High Commissioner. UN Human Rights Treaty Bodies call for human rights approach in fighting COVID-19. Genebra, 2020. Disponível em:

https://www.ohchr.org/en/NewsEvents/Pages/Di splayNews.aspx? NewsID=25742\&LangID=. Acesso em: 05 jun. 2020.

UNITED NATIONS. Shared Responsibility, Global Solidarity: Responding to the socio-economic impacts of COVID-19. March 2020a. Disponível em:

https://unsdg.un.org/sites/default/files/202003/SG-Report-Socio-Economic-Impact-ofCovid19.pdf. Acesso em: 05 jun. 2020.

UNITED NATIONS. COVID-19 and Human Rights: We are all in this Together. April, 2020b.

Disponivel em:

https://unsdg.un.org/resources/covid-19-andhuman-rights-we-are-all-together. Acesso em: 05 jun. 2020.

WHO. World Health Organization. Preparedness, prevention and control of coronavirus disease (COVID-19) for refugees and migrants in noncamp settings: Interim guidance, 2020.

Disponível em:

https://apps.who.int/iris/rest/bitstreams/127503

9/retrieve. Acesso em: 05 jun. 2020. 